\title{
Does dexamethasone enhance control of acute cisplatin induced emesis by ondansetron?
}

\author{
J F Smyth, R E Coleman, M Nicolson, W M Gallmeier, R C F Leonard, M A Cornbleet, S G Allan, \\ B K Upadhyaya, U Bruntsch
}

\begin{abstract}
Objective-To determine the contribution of dexamethasone to the efficacy of the 5-hydroxytryptamine antagonist ondansetron in control of cisplatin induced nausea and vomiting.
\end{abstract}

Design-Randomised double blind crossover study.

Setting-Two cancer centres in teaching hospitals, one in the United Kingdom and the other in Germany.

Subjects -100 patients (53 men and 47 women) new to cisplatin chemotherapy, 84 of whom completed two consecutive courses of chemotherapy.

Interventions-Patients were given intravenous dexamethasone $(20 \mathrm{mg})$ or physiological saline with intravenous ondansetron $8 \mathrm{mg}$ before cisplatin, then ondansetron $1 \mathrm{mg} / \mathrm{h}$ for 24 hours. Oral ondansetron $8 \mathrm{mg}$ was taken three times daily on days $2-6$.

Main outcome measures-Incidence of complete or major control of emesis (0-2 episodes in the 24 hours after chemotherapy).

Results -Complete or major control was obtained in 49 out of $71(69 \%)$ of patients after receiving ondansetron plus dexamethasone compared with $\mathbf{4 0}$ out of $71(56 \%)$ when they were given ondansetron alone $(p=0.012)$. This effect was most pronounced in the first 12 hours after chemotherapy. Patients receiving the combination also had significantly less nausea. Of the 53 patients who expressed a preference, $38(72 \%)$ preferred the combination treatment $(p=0.002)$ to ondansetron alone. The effect of ondansetron on delayed emesis was less pronounced.

Conclusions - Dexamethasone makes a significant contribution to the efficacy of ondansetron in the control of acute platinum induced emesis.

\section{Introduction}

Cisplatin is one of the most emetogenic chemotherapeutic agents and treatment with high doses produces acute nausea and vomiting in all patients within 24 hours unless antiemetic drugs are used. ${ }^{1}$ Partial control of emesis can be obtained, but none of the widely used antiemetic drugs is fully effective. Furthermore, high doses of antiemetic drugs such as metoclopramide, which act by antagonism at central dopamine receptors, may produce extrapyramidal effects in up to $10 \%$ of patients.

Ondansetron is a selective 5-hydroxytryptamine receptor antagonist which is devoid of any effects on dopamine receptors. ${ }^{3}$ It can usually prevent emesis and nausea produced by chemotherapy ${ }^{4}$ or radiotherapy. ${ }^{5}$ In controlled studies ondansetron has been shown to be superior to high dose metoclopramide in preventing cisplatin induced emesis and nausea ${ }^{6}$ However, emesis and nausea in about $30 \%$ of patients remains inade- quately controlled by ondansetron. Dexamethasone is known to have antiemetic properties, especially when used in high dosage. ' Its mechanism of action is unknown, but we have shown that dexamethasone can enhance the efficacy of metoclopramide in treating cisplatin induced emesis.

In a recent study in ferrets treated with cyclophosphamide considerable enhancement of the antiemetic effect of a suboptimal dose of ondansetron was shown when it was combined with dexamethasone. ${ }^{9}$ Recent pilot studies have shown an increased clinical effectiveness of ondansetron when given with dexamethasone for preventing emesis in patients who were refractory to ondansetron treatment. ${ }^{111}$

We compared the clinical efficacy and safety of ondansetron alone and in combination with dexamethasone in the prophylaxis of nausea and vomiting in the first 24 hours after cancer chemotherapy with cisplatin. We also studied the efficacy and safety of ondansetron alone in the prophylaxis of delayed nausea and vomiting (on days 2-6) induced by cisplatin.

\section{Patients and methods}

The study comprised 100 patients $(53$ men and 47 women) with various malignancies and a median age of 51 years (range 18-74 years) who were receiving their first course of cancer chemotherapy with cisplatin 100 $\mathrm{mg} / \mathrm{m}^{2}$ over one hour and scheduled to receive at leas two courses. It was conducted at one centre in the United Kingdom and one in Germany and wa approved by their respective local ethics committees Consent was obtained from each patient before participation in the study. Patients were considered ineligible if they were clinically jaundiced, had active peptic ulceration, had vomited in the 24 hours before chemotherapy or had received antiemetics during this period, or were receiving concurrent benzodiazepines (excep for night sedation).

The study had a randomised, double blind, crossover design. Randomisation was computer generated by using a patient allocation for clinical trials program All patients were inpatients for at least 24 hours. According to the randomisation code, patients first received either intravenous dexamethasone $(20 \mathrm{mg})$ or physiological saline 30 minutes before receiving cisplatin. The injections were blinded by the hospital pharmacist. This was followed by a slow intravenous injection of $8 \mathrm{mg}$ of ondansetron and an infusion of ondansetron at $1 \mathrm{mg} /$ hour for 24 hours, starting 15 minutes before the cisplatin infusion. At the end of the 24 hour infusion of ondansetron patients started taking oral ondansetron $(8 \mathrm{mg})$, which was continued three times a day for five days (days 2-6), on an outpatient basis.

Patients were monitored for the first 24 hours, and the time and number of vomits and retches recorded. If 
any patient totally failed to respond - that is, experienced more than five episodes of vomits or retches, or both, in the 24 hours after starting to receive cisplatin - then he or she could be given an antiemetic as a rescue medication. At the end of the first 24 hours an overall assessment of nausea and appetite was made by the patient according to the scale shown in the box. Any adverse events during this period were recorded.

A blood sample was taken for routine haematological testing; measurement of urea, creatinine, and electrolyte concentrations; and liver function tests (bilirubin, concentration and aspartate aminotransferase, alanine aminotransferase, and $\gamma$-glutamyltransferase activities) before treatment and at 24 hours and seven days later. On days 2-6 the patients were asked to complete a diary card daily for each preceding 24 hour period of the outpatient oral treatment. The number of vomits or retches, graded values for nausea and appetite, the number of ondansetron tablets taken, and any other symptoms of note were recorded. Patients receiving modified doses of cisplatin (because of renal toxicity) in the second or subsequent courses were allowed to continue. After completion of the second course patients were asked to indicate which antiemetic treatment they preferred. The study code was not broken and patients continued to receive four further courses of randomised, double blind, crossover treatments.

A total of 100 patients were estimated to give the study a power of 0.8 at the $5 \%$ significance level to discriminate between overall success rates $(0-2$ emetic episodes) of $65 \%$ with ondansetron plus dexamethasone and $45 \%$ with ondansetron alone. Sixty patients were recruited from the British centre and 40 from the German centre. The analyses included tests for interaction between treatment and centre. The primary response to antiemetic treatment was based on the percentage of patients who experienced complete or major (0-2 emetic episodes) control of emesis over the first 24 hours. An emetic episode was defined as any vomit productive of liquid or 1-5 retches within a five minute period. The time to first emetic episode during the first 24 hours was calculated from the records of vomits and retches. If the number of emetic episodes was 0 , the time to first emetic episode was censored at 24 hours and an arbitrary value of 25 hours used in the analysis of ranked times. Data were analysed on the basis of intention to treat for all patients completing the first two courses and for patients considered fully evaluable by adequate protocol compliance over those courses.

The number of emetic episodes was compared between treatments by using non-parametric methods for a crossover design based on Wilcoxon rank sum tests. ${ }^{12}$ The response to treatment was graded a success if the patient experienced $0-2$ emetic episodes and a failure otherwise. These binary response data were analysed according to methods appropriate to the crossover design. ${ }^{13}$ Th The patient preference data were analysed by Prescott's method. ${ }^{13}$ Emetic response data from the first course only were also analysed by Mantel-Haenszel $\chi^{2}$ test.

\section{Results}

Of the 100 patients entered into the study, 84 completed two consecutive courses; 65 , three courses; 46 , four courses; 28 , five courses; and 21 , six courses. Demographic characteristics at entry including tumour site(s) were similar for the 53 patients starting treatment with ondansetron and the 47 starting with ondansetron plus dexamethasone. Seventy one of the 84 patients completing two courses of chemotherapy showed adequate compliance with the protocol over both courses. Table I gives the reasons for 16 patients
Grading of nausea, emesis, and appetite after cisplatin chemotherapy

Vomits/retches: Appetite:

$0=$ Complete control $\quad 1=$ Better than usual

1-2= Major control

3-5 $=$ Minor control

$2=$ As usual

$>5=$ Failure

$3=$ Could take some solids $4=$ Could take only liquids

Nausea:

None

Mild - did not interfere with normal daily life

Moderate-interfered with normal daily life

Severe - bedridden due to nausea

not progressing to the second chemotherapy course $\frac{\bar{c}}{\widehat{\phi}}$ and 13 patients not being considered fully evaluable.

The results below refer to efficacy based on intention $\overbrace{}^{\circ}$ to treat analysis. The results for the fully evaluable $\vec{\circ}$ patients were similar and are referenced as appropriate.

\section{EMETIC RESPONSE}

Table II shows the control of emesis during the $24 \dot{\omega}$ hours after treatment with cisplatin and table III thec primary response rates in the 84 patients completingo both courses. There was no evidence of treatment by period interaction. The fully evaluable patients alsoshowed a significantly greater response with the com $\overrightarrow{\mathrm{N}}$ bination of ondansetron plus dexamethasone $\left(49 / 71^{\mathrm{\omega}}\right.$ $69 \%)$ than with ondansetron alone $(40 / 71,56 \%)(\mathrm{p}=-$ 0.035 ). Analysis of course 1 data (as parallel group) ${ }^{2}$ showed complete plus major response in 32 out of 530

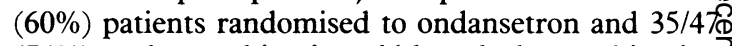
$(74 \%)$ to the combination. Although the combination provided a clinically superior response, the power was insufficient to show a significant difference $(p=0 \cdot 137)$.

The time to the first emetic episode was delayed withe dexamethasone $(\mathrm{p}<0 \cdot 001) ; 33(39 \%)$ of patients given

TABLE I-Reasons for withdrawal of patients after course 1 and protocol violations during courses 1 or 2

\begin{tabular}{|c|c|c|}
\hline & \multicolumn{2}{|c|}{ Treatment sequence } \\
\hline eason & $\begin{array}{c}\text { Ondansetron alone } \\
\text { then ondansetron } \\
\text { plus } \\
\text { dexamethasone }\end{array}$ & $\begin{array}{c}\text { Ondansetron plus } \\
\text { dexamethasone } \\
\text { then ondansetron } \\
\text { alone }\end{array}$ \\
\hline \multicolumn{3}{|c|}{ Not progressing beyond course 1} \\
\hline $\begin{array}{l}\text { eath } \\
\text { isplatin toxicity } \\
\text { oor emesis control } \\
\text { hysician's decision } \\
\text { evere constipation }\end{array}$ & $\begin{array}{l}3 \\
2 \\
1 \\
3\end{array}$ & $\begin{array}{l}2 \\
2 \\
2 \\
1\end{array}$ \\
\hline \multicolumn{3}{|c|}{ Protocol violation during course 1 or 2} \\
\hline $\begin{array}{l}\text { Concurrent benzodiazepines } \\
\text { retreatment vomiting } \\
\text { ncorrect cisplatin infusion } \\
\text { rior cisplatin chemotherapy } \\
\text { Ondansetron infusion }<24 \mathrm{~h} \\
\text { Concurrent antiemetics }\end{array}$ & $\begin{array}{l}3 \\
2 \\
1 \\
1 \\
1\end{array}$ & $\begin{array}{l}1 \\
1 \\
2 \\
1\end{array}$ \\
\hline
\end{tabular}

TABLE II-Control of emesis and nausea during 24 hours after treatment with cisplatin. Figures are numbers (percentages) of patients

\begin{tabular}{|c|c|c|}
\hline Response & $\begin{array}{l}\text { Ondansetron } \\
\text { alone }\end{array}$ & $\begin{array}{c}\text { Ondansetron } \\
\text { plus } \\
\text { dexamethasone }\end{array}$ \\
\hline \multicolumn{3}{|c|}{ Emesis control ${ }^{\star}$ (vomits and retches): } \\
\hline Complete ( 0 episodes $)$ & $35(42)$ & $49(58)$ \\
\hline Major ( $1-2$ episodes $)$ & $12(14)$ & $9(11)$ \\
\hline Minor (3-5 episodes) & $10(12)$ & $7(8)$ \\
\hline Failure ( $>5$ episodes $)$ & $27(32)$ & $19(23)$ \\
\hline \multicolumn{3}{|l|}{ Nausea gradet: } \\
\hline None & $27(33)$ & $43(52)$ \\
\hline Mild & $26(32)$ & $20(24)$ \\
\hline Moderate & $25(30)$ & $17(21)$ \\
\hline Severe & $4(5)$ & $2(3)$ \\
\hline
\end{tabular}

${ }^{\star}$ Complete plus major; $\mathrm{p}=0.012$ (Prescott's test based on binary response) $t p<0.001$ (Prescott's test for treatment with better grade). 
TABLE III - Number of patients with complete or major control of acute emesis after courses 1 and 2

\begin{tabular}{lccccc}
\hline & \multicolumn{5}{c}{ Response (course 1, course 2)^} \\
\cline { 2 - 6 } Treatment sequence & $\begin{array}{c}\text { Failure, } \\
\text { failure }\end{array}$ & $\begin{array}{c}\text { Failure, } \\
\text { success }\end{array}$ & $\begin{array}{c}\text { Success, } \\
\text { failure }\end{array}$ & $\begin{array}{c}\text { Success, } \\
\text { success }\end{array}$ & Total \\
\hline Ondansetron alone then ondansetron plus dexamethasone & 12 & 5 & 6 & 21 & 44 \\
Ondansetron plus dexamethasone then ondansetron alone & 8 & 0 & 12 & 20 & 40 \\
\hline Total & 20 & 5 & 18 & 41 & 84 \\
\hline
\end{tabular}

*Success $=0-2$ emetic episodes, failure $=>2$ emetic episodes.

Success rates: $47 / 84(56 \%)$ with ondansetron, $58 / 84(69 \%)$ with ondansetron plus dexamethasone. Difference $=11 / 84$ $(13 \%)$; approximate $95 \%$ confidence interval 2 to $24 ; \chi^{2}=6 \cdot 37, \mathrm{df}=1, \mathrm{p}=0 \cdot 012$.

TABLE IV-Patients' preference for treatment by treatment sequence

\begin{tabular}{lccc}
\hline & \multicolumn{3}{c}{ Preferred treatment } \\
\cline { 2 - 4 } & $\begin{array}{c}\text { Ondansetron } \\
\text { alone }\end{array}$ & $\begin{array}{c}\text { Ondansetron } \\
\text { plus } \\
\text { dexamethasone }\end{array}$ & $\begin{array}{c}\text { No } \\
\text { preference }\end{array}$ \\
\hline $\begin{array}{c}\text { Ondansetron alone then } \\
\text { ondansetron plus } \\
\text { dexamethasone }\end{array}$ & 7 & 19 & 16 \\
$\begin{array}{l}\text { Ondansetron plus } \\
\text { dexamethasone then } \\
\text { ondansetron alone }\end{array}$ & 8 & $19^{\star}$ & 12 \\
\hline
\end{tabular}

${ }^{\star} \mathrm{p}=0 \cdot 002$.

ondansetron alone experienced an emetic episode within the first 12 hours compared with $10(12 \%)$ given the combination. The median times to the first emetic episode for the respective treatments were 18.9 hours and $>24$ hours. These differences were also evident in the fully evaluable patients.

\section{NAUSEA GRADE}

Eighty three $(99 \%)$ patients had not had any pretreatment for nausea. The grades of nausea for each treatment 24 hours after treatment with cisplatin are shown in table II. Of the 45 patients with different grades when receiving the two treatments, 35 showed a better grade with ondansetron plus dexamethasone than with ondansetron alone ' $(\mathrm{p}<0.001)$. For the 38 fully evaluable patients who had different grades when receiving the two treatments, 28 favoured the combination $(p=0.003)$.

\section{TREATMENT PREFERENCE}

Table IV gives the distribution of patient preference. Preference for the combination was significant $(38 / 53(68 \%) ; p=0.017)$ in the fully evaluable group.

\section{DELAYED EMESIS AND NAUSEA}

For both treatment groups continuing to take oral ondansetron the control of emesis and nausea over days 2-6 was similar. Despite effective acute control delayed nausea and vomiting was still a major problem. On day 2 only $23 / 84(27 \%)$ of patients experienced no vomiting and $11(13 \%)$ reported no nausea; $37(46 \%)$ of patients had $>2$ vomits, and $47(56 \%)$ had moderate or severe nausea. During days 3-6, the severity of emesis subsided, but on day $6,24(29 \%)$ of patients were still vomiting and $35(42 \%)$ experiencing nausea.

\section{SAFETY}

Adverse events reported during treatment for up to six courses were headache in $17 / 98(17 \%)$ patients receiving ondansetron alone and $13 / 91$ (14\%) patients receiving ondansetron plus dexamethasone; constipation in $15 / 98(15 \%)$ and $21 / 91(23 \%)$ patients; diarrhoea in 16/98 (16\%) and 5/91 (5\%) patients; and transient increases in the results of liver function tests in 15/98 $(15 \%)$ and $18 / 91$ (19\%) patients respectively. Two major adverse events were thought probably to be related to antiemetic treatment. One patient had severe constipation after the first course and required readmission to the hospital and withdrawal from the study. The other patient had a rise in aspartate aminotransferase activity from 13 to $111 \mathrm{U} / \mathrm{l}$ at 24 hours after starting treatment with intravenous ondansetron and did not proceed with oral treatment; the activity returned to baseline level spontaneously and the patient continued in the study for a further two courses.

\section{Discussịon}

There were significant improvements in the antiemetic efficacy of ondansetron when it was given in? combination with dexamethasone. Corticosteroids possess limited intrinsic antiemetic activity but when? given in combination substantially enhance the efficacy of several antiemetic drugs. ${ }^{81516}$ The exact mechanismes of the antiemetic action of corticosteroids when givensingly or in combination is not clearly understood.

In this study of patients receiving chemotherapy $\vec{\omega}$ comprising $100 \mathrm{mg} / \mathrm{m}^{2}$ of cisplatin, ondansetron completely prevented acute emesis (during the first $24 \stackrel{3}{3}$ hours after treatment) in $42 \%$ of patients compared with $58 \%$ of those receiving dexamethasone. The combination of ondansetron and dexamethasone alsog provided significantly greater complete plus major control ( 0 -2 episodes) of acute emesis than ondansetron alone $(69 \% v 56 \%)$. The differences in antiemetic efficacy were significant for analysis both by intention to treat $(p=0.012)$ and of the fully evaluable $(p=0.035)^{\circ}$ patient population. Although there was no significant $v$ evidence of any treatment and centre interactions examination of the data on efficacy of treatment and treatment preference showed that the advantage of dexamethasone was more apparent in the British centre.

Our observations support, although do not match,, the data of Roila et al. ${ }^{17}$ In their study complete control of cisplatin induced emesis was achieved in $91 \%$ ofo patients treated with a combination of ondansetron and $s$ dexamethasone compared with $64 \%$ given ondansetrono alone. Also, in agreement with this study, acute nauseä induced by cisplatin was controlled more effectively by $\varrho$ ondansetron when it was given with dexamethasone. $\overrightarrow{0}$ In all, $80 \%$ of patients receiving the combination treatment graded their nausea within 24 hours as none or mild compared with $68 \%$ of patients treated with? ondansetron alone.

Double blind crossover studies can be useful in providing information such as a patient's preference ${ }_{0}$ for treatment. In this study patient preference was assessed after the completion of both treatmenti courses. Of the 53 patients indicating a preference, $38(72 \%)$ preferred the combination treatment com-o pared with $15(28 \%)$ who preferred treatment with ondansetron alone $(\mathrm{p}=0.002)$.

The superior control of emesis with ondansetron and dexamethasone in the first 24 hours did not seem to influence the pattern of delayed nausea and vomiting, $\mathcal{O}$ which still affected most of the patients, being particu- స్ట larly troublesome on day two. The persistence of delayed nausea and vomiting despite treatment witho ondansetron suggests that a different mechanism(s), and presumably neurotransmitter(s), are involved. $\mathrm{A}^{\stackrel{\rho}{+}}$ short course of oral dexamethasone has been shown to믐 enhance the efficacy of metoclopramide in treating delayed nausea and vomiting. ${ }^{1 \mathrm{~T}}$ The role of prolongedo administration of the study drugs should be investigated in a randomised controlled study.

Ondansetron given intravenously with or without dexamethasone followed by oral treatment as a singleo agent was safe and tolerated well for up to six courses of chemotherapy. Mild or moderate headache, consti-을 pation, and diarrhoea were the most commonly reported transient adverse events with both treatments. Any observed increases in serum activities of 
aspartate aminotransferase, alanine aminotransferase, or $\gamma$-glutamyltransferase were transient and asymptomatic.

We conclude that dexamethasone clearly improves the antiemetic efficacy of ondansetron for the control of acute nausea and vomiting after high dose chemotherapy with cisplatin. It remains to identify the optimum antiemetic chedule to minimise delayed emesis as the next step in improving the acceptability of treatment to patients.

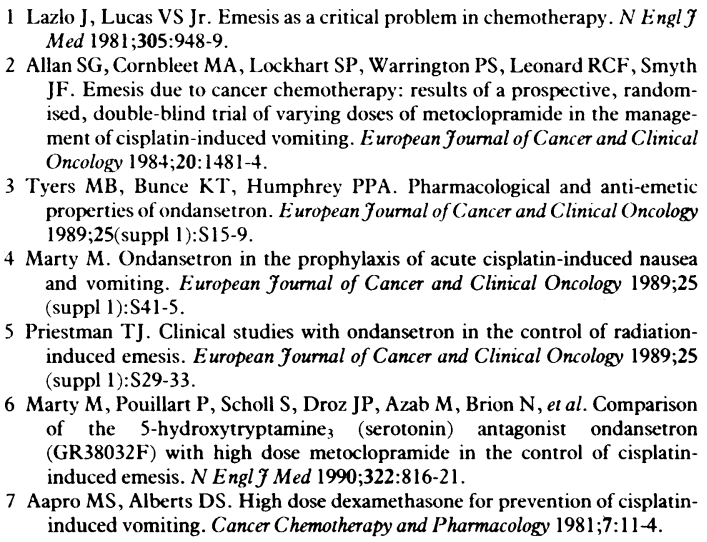
ised, double-blind trial of varying doses of metoclopramide in the management of cisplatin-induced vomiting. European fournal of Cancer and Clinical Oncology 1984;20:1481-4.

3 Tyers MB, Bunce KT, Humphrey PPA. Pharmacological and anti-emetic properties of ondansetron. European fournal of Cancer and Clinical Oncology 1989;25(suppl 1):S15-9.

4 Marty $M$. Ondansetron in the prophylaxis of acute cisplatin-induced nause and vomiting. European fournal of Cancer and Clinical Oncology 1989;25 (suppl 1):S41-5

5 Priestman TJ. Clinical studies with ondansetron in the control of radiationinduced emesis. European fournal of Cancer and Clinical Oncology 1989;25 (suppl 1):S29-33

6 Marty M, Pouillart P, Scholl S, Droz JP, Azab M, Brion N, et al. Comparison of the 5-hydroxytryptamine, (serotonin) antagonist ondansetron GR38032F) with high dose metoclopramide in the control of cisplatininduced emesis. N Engl f Med 1990;322:816-21.

7 Aapro MS, Alberts DS. High dose dexamethasone for prevention of cisplatininduced vomiting. Cancer Chemotherapy and Pharmacology 1981;7:11-4.

8 Allan SG, Cornbleet MA, Warrington PS, Golland IM, Leonard RCF, Smyth JF. Dexamethasone and high dose metoclopramide: efficacy in controllin cisplatin-induced nausea and vomiting. BMF 1984;289:878-9.

9 Hawthorn J, Cunningham D. Dexamethasone can potentiate the anti-emetic action of a $5 \mathrm{HT}_{3}$ receptor antagonist on cyclophosphamide-induced vomiting in the ferret. Br $\mathcal{F}$ Cancer 1990;61:56-60.

10 Cunningham D, Turner A, Hawthorn J, Rosin RD. Ondansetron with and without dexamethasone to treat chemotherapy-induced emesis. Lancel 1989; i: 1323 .

11 Smith DB, Newlands ES, Spruyt OW, Begent RHJ, Rustin GJS, Mellor B et al. Ondansetron (GR38032F) plus dexamethasone: effective anti-emetic prophylaxis for patients receiving cytotoxic chemotherapy. Br $\mathrm{f}$ Cancer prophylaxis for

12 Koch GG. The use of non-parametric methods in the statistical analysis of the two-period change-over design. Biometrics 1972;28:577-84

13. Prescott RJ. The comparison of success rates in crossover trials in the presence of an order effect. Applied Statistics 1981;30:9-15.

14 Hills M, Armitage P. The two-period crossover clinical trial. $\mathrm{Br}$ f Clin Pharmacol 1979;8:7-20.

15 Allan SG, Farquhar DF, Harrison DJ, Leonard RCF. Anti-emetic efficacy of dexamethasone in combination for outpatients receiving combination chemotherapy. Cancer Chemotherapy and Pharmacology 1986;18:86-7.

16 Benrubi GI, Norvell M, Nuss RC, Robinson H. The use of methylprednisolone and metoclopramide in control of emesis in patients receiving cisplatin. Gynecol Oncol 1985;21:306-13.

17 Roila F, Tonato M, Cognetti F, Cortesi F, Favalli G, Marangolo K, et al. A double-blind multi-centre randomised crossover study comparing the anti-emetic efficacy and tolerability of ondansetron vs ondansetron plus dexame dexamethasone in cisplatin-treated cancer patien.

18 Kris $M G$ G Controlling delayed vomiting: double-blind, randomised trial comparing placebo, dexamethasone alone, and metoclopramide plus dexamethasone in patients receiving cisplatin. $\mathcal{F}$ Clin Oncol 1989;7:108-14.

(Accepted 25 September 1991)

\section{Bronchodilator treatment in moderate asthma or chronic bronchitis: continuous or on demand? A randomised controlled study}

Constant P van Schayck, Edward Dompeling, Cees L A van Herwaarden, Hans Folgering, Andre L M Verbeek, Henk J M van der Hoogen, Chris van Weel

\section{Abstract}

Objective-To examine the effect of bronchodilator treatment given continuously versus on demand on the progression of asthma and chronic bronchitis and to compare the long term effects of a $\beta_{2}$ adrenergic drug (salbutamol) and an anticholinergic drug (ipratropium bromide)

Design-Two year randomised controlled prospective crossover study in which patients were assigned to one of two parallel treatment groups receiving continuous treatment or treatment on demand.

Setting-29 general practices in the catchment

Nijmegen University, PO Box 9101, Nijmegen 6500 HB, The Netherlands Constant $P$ van Schayck, PHD, research lecturer, department of general practice Edward Dompeling, MD, research fellow, department of general practice

Cees L A van Herwaarden, $\mathrm{MD}$, professor of pulmonology Hans Folgering, MD, head, pulmonary function laboratory Andre L M Verbeek, MD, senior lecturer, department of epidemiology

Henk J M van der Hoogen, statistician, department of general practice

Chris van Weel, MD, professor of general practice

Correspondence to: Dr C P van Schayck.

Patients -223 patients aged $\geqslant 30$ with moderate airway obstruction due to asthma or chronic bronchitis, selected by their general practitioners.

Interventions-1600 $\mu \mathrm{g}$ salbutamol or $160 \mu \mathrm{g}$ ipratropium bromide daily (113 patients) or salbutamol or ipratropium bromide only during exacerbations or periods of dyspnoea (110). No other pulmonary treatment was permitted.

Main outcome measures-Decline in ventilatory function and change in bronchial responsiveness, respiratory symptoms, number of exacerbations, and quality of life.

Results-Among 144 patients completing the study, after correction for possible confounding factors the decline in forced expiratory volume in one second was $-0.0721 /$ year in continuously treated patients and -0.0201 year in those treated on demand $(p<0.05)$, irrespective of the drug. The difference in the decline in patients with asthma was comparable with that in patients with chronic bronchitis (asthma: 0.092 $v-0.025 \mathrm{l}$ /year; chronic bronchitis: $-0.082 v-0.031$ 1/year). Bronchial responsiveness increased slightly $(0.4$ doubling dose) with continuous treatment in chronic bronchitis, but exacerbations, symptoms, and quality of life were unchanged. Salbutamol and ipratropium bromide had comparable effects on all variables investigated.

Conclusions-Continuous bronchodilator treatment without anti-inflammatory treatment accelerates decline in ventilatory function. Bronchodilators should be used only on demand, with additional corticosteroid treatment, if necessary.

\section{Introduction}

Asthma and chronic bronchitis are considered to be progressive diseases. ${ }^{12}$ The hypothesis has been put forward that early continuous bronchodilator treatment of reversible airflow obstruction will improve their prognosis, ${ }^{3}$ and this led to the recommendation to use continuous inhaled $\beta_{2}$ adrenergic drugs as a first step in treating chronic airflow obstruction. ${ }^{45}$ How ever, recent reports indicate adverse effects caused by continuous use of $\beta_{2}$ adrenergic inhalants, ${ }^{6-8}$ resulting in advice to reserve these drugs for treatment on demand ${ }^{89}$ Neither of these contradictory recommendations are based on evidence from intervention studies lasting long enough to establish an effect on decline in ventilatory function, which is generally believed to be the most important measure of progression of asthma or chronic bronchitis. Another question is which type of bronchodilator inhalant is more efficacious in long term treatment of asthma or chronic bronchitis: an anticholinergic drug or a $\beta_{2}$ adrenergic drug? Until now only the immediate bronchodilating effects of these drugs have been compared. Adverse effects of the continuous use of bronchodilators have 